\title{
A MATEMÁTICA NAS TURMAS DE PROEJA: O LÚDICO COMO FACILITADOR DA APRENDIZAGEM
}

\author{
Silvia Regina Pereira de Mendonça \\ Professora de Matemática do IFRN. Licenciada em Matemática pela FICAB (RJ); \\ Especialista em Educação Infantil e Alfabetização; Mestre em Educação (Educação \\ Matemática) pelo Programa de Pós-Graduação em Educação da UFRN. Coordenadora do \\ Grupo de Pesquisa em Ciências Naturais e Matemática do IFRN - Campus Santa Cruz. \\ E-mail: silvia.mendonca@ifrn.edu.br
}

\begin{abstract}
RESUMO
O presente relato aborda a perspectiva de dar ao lúdico e às atividades criativas um papel de destaque no processo de ensino-aprendizagem da matemática e sua contribuição para a construção do conhecimento matemático nas turmas de PROEJA Refrigeração e Climatização, do IFRN Campus Santa Cruz. Nosso objetivo fundamental com este trabalho foi tanto o de apresentar um novo recurso metodológico, bem como sua aplicação em sala de aula. Certas competências e habilidades importantes ao desenvolvimento pessoal e a aprendizagem podem ser encontradas em diversas atividades. Desta forma, este estudo partiu de experiências bem sucedidas que abordam a importância de paródias, mágicas e brincadeiras diversas nas aulas de Matemática, ressaltando tanto o papel do professor, quanto das atividades e suas especificidades. Entende-se que o lúdico é uma importante contribuição para o desenvolvimento de todos e que deve ser levado em consideração dentro do contexto escolar, independente da idade, sob constante elaboração e reelaboração no seu planejamento, principalmente como recurso didático. Contudo, é necessário que o professor tenha conhecimento e segurança para que, mesmo na dimensão lúdica, essas atividades tenham caráter didático, para servirem de base para um trabalho pedagógico.
\end{abstract}

PALAVRAS-CHAVE: PROEJA, Aprendizagem significativa, Ensino-aprendizagem, Interação, Recurso didático.

\section{MATHEMATICS IN PROEJA CLASSES: PLAYING AS A LEARNING ENABLER}

\begin{abstract}
This paper discusses the perspectives of giving a key role to playful and creative activities in the process of teaching and learning Mathematics, as well as their contributions to the building of mathematical knowledge in vocational classes of adult education (PROEJA) in the Refrigeração e Climatização course at IFRN, Santa Cruz campus. Our fundamental aims in this work were both presenting a new methodological tool and showing its applications in the classroom. Some competences and skills considered important for the learning process and personal development can be identified in many of those activities. This paper evolved from such successful experience with the use of parodies, magic tricks and several games during Math classes, giving emphasis to the teacher's role as well as to the activities themselves and their particularities. We understand that playing represents an important contribution to the development of all students and must be taken into consideration in the school context, no matter the age group, always undergoing
\end{abstract}


continuous formulation and reformulation during planning, especially as a teaching aid. Nevertheless, the teacher must have proper knowledge and confidence to ensure that these activities of ludic dimension still keep their didactic nature and serve to educational purposes.

KEY-WORDS: PROEJA/Adult education, Significant learning, Teaching and learning process, Interaction, Teaching aids. 


\section{A MATEMÁTICA NAS TURMAS DE PROEJA: O LÚDICO COMO FACILITADOR DA PRENDIZAGEM}

\section{INTRODUÇÃO}

Desde o surgimento da humanidade, a Matemática é conhecida pelos homens. Eles utilizavam vários objetos e estabeleciam relações em seu meio, porém, com o passar do tempo, os conhecimentos matemáticos foram se desvinculando da realidade nos ambientes educacionais. Para acompanhar as evoluções que avançam a cada dia, faz-se necessário que nós, educadores, mudemos nossa maneira de ensinar a Matemática, que é vista pela maioria dos alunos como quase inacessível, como uma das disciplinas mais difíceis da grade curricular. De acordo com Brasil (1997), tal visão pode ser modificada desde que haja compromisso por parte dos educadores com uma proposta de trabalho criativa, que investigue e analise os problemas político-sociais da atualidade e esteja sempre verificando o que se passa no comércio, na indústria, nos jornais, etc.

O professor deve conscientizar-se de que o foco principal do processo ensinoaprendizagem é o desenvolvimento integral do aluno e não apenas a simples transmissão do conteúdo. Daí surge, então, a necessidade de a escola apresentar atividades pedagógicas que propiciem a participação efetiva de todos, com alegria, imaginação e criatividade.

O baixo rendimento de alguns alunos em relação à Matemática vem acompanhado de vários elementos relacionados à metodologia, a políticas públicas, a distorções curriculares, ao conteúdo, ao próprio professor, entre outros. Na maioria das vezes, essa disciplina é abordada de forma mecânica como um conhecimento pronto e acabado, condicionando dessa forma alguns alunos a resolverem exercícios sem questioná-los, ficando o resolver por resolver. Mesmo porque a forma que "aprenderam" não dá espaço a questionamentos. O aluno, neste caso, não é estimulado a realizar raciocino lógico, o que é igualmente prejudicial à sua formação.

Concordamos com Nuñes e Ribeiro (2004, p.30) quando afirmam que "a ação educativa pode ser melhorada a partir da construção de um novo saber, saber fazer não é só para aprender, mas para aprender a aprender". Sendo assim, os conteúdos matemáticos podem ser aprendidos por qualquer pessoa, desde que esta possa identificar, definir, classificar, analisar e expor seus pensamentos, tendo o professor que dar tal oportunidade, propiciando um ambiente de manipulação, investigação e formulação de hipóteses, a fim de que o aluno adquira uma aprendizagem significativa ${ }^{1}$. O professor, neste caso, será apenas um auxiliador.

De acordo com os Parâmetros Curriculares Nacionais (PCNs), o "homem para exercer cidadania deve saber calcular, medir, argumentar, raciocinar e tratar informações estatisticamente" (BRASIL, 1997), Partindo desse pressuposto, acreditamos que, para obter êxito no processo ensino-aprendizagem, o aluno deve realizar experiências concretas, vivenciando dinamicamente os conteúdos que lhe forem propostos, respondendo positivamente ao mundo que o rodeia, através de conceitos construídos e interiorizados,

\footnotetext{
${ }^{1} \mathrm{O}$ mecanismo interno do pensamento vinculado à aprendizagem significativa é explicado pela teoria de assimilação de David P. Ausubel (1989) mediante a relação entre a estrutura cognitiva do aprendiz e as novas informações com as quais estabelece relações não arbitrárias e substantivas (NUÑES E RIBEIRO, 2004, p.30).
} 
manipulando uma série de materiais concretos, que servirão como auxiliares no desenvolvimento de seu raciocínio. A Matemática tem por objetivo desenvolver o espírito criativo, o raciocínio lógico e o pensar matematicamente, construindo variados significados a partir das diferentes formas de utilização no cotidiano do aluno.

Desse modo, sempre que possível relacionamos a Matemática com a prática e com jogos e brincadeiras diversas, unindo o lúdico ao desenvolvimento do raciocínio matemático, tendo como base as propostas inovadoras da Educação Matemática. Os debates contemporâneos, em nossa forma de perceber e de pensar, levam ao limite essa questão. A Matemática está integrada ao sistema científico, tecnológico, industrial, militar, econômico, político, cujo processo sempre foi apoiado por tais sistemas, dando a essa disciplina um caráter universal e agradável, sempre que possível (D’AMBROSIO, 2001).

Vemos aqui reforçada a afirmação de que a Matemática é viva e está na vida. Com esse pensamento e trabalhando em turmas de PROEJA ${ }^{2}$ Refrigeração e Climatização, do IFRN Campus Santa Cruz, vivenciamos e aplicamos a relação entre Matemática e cotidiano, ou seja, como os conteúdos matemáticos são utilizados nas atividades diárias. Os alunos estudam a Matemática em receitas de comidas, operações financeiras em feiras ou compras, em geral, comparando o preço de cestas básicas com o dos alimentos no varejo, realizando mágicas, paródias e jogos diversos. Percebemos o quanto os alunos se envolvem nessas atividades e o quanto este tipo de metodologia de ensino desperta o interesse e o desenvolvimento do raciocínio matemático.

A necessidade de utilizar atividades lúdicas ${ }^{3}$ contribui para uma aprendizagem mais satisfatória nesta disciplina, que é tida como uma das mais difíceis de ser compreendida. Isso nos conduziu ao desenvolvimento deste trabalho na tentativa de mostrar caminhos para o ensino da Matemática, de maneira mais prazerosa e gratificante tanto para o aluno quanto para o professor, fortalecendo a relação de troca de conhecimentos entre ambos e estabelecendo uma relação harmoniosa e respeitosa.

Surge, então, a necessidade de a escola criar oportunidades ao desenvolvimento matemático. Essa visão é caracterizada por atividades experimentais, brincadeiras, mágicas, entre outras atividades realizadas pelo aluno e pelo professor, com o intuito de construir conceitos, levando à discussão de questões, relacionando conteúdos escolares com atividades vivenciadas no cotidiano, onde o aluno desenvolve sua própria linguagem relacionada à compreensão, interpretando e realmente aprendendo a realidade matemática.

A partir do momento em que houver conscientização dos professores sobre a importância do trabalho matemático junto com atividades lúdicas, saberemos que, além de dinâmicas, as aulas de matemática serão muito mais atrativas e o objetivo da aprendizagem será conquistado: os alunos não apenas memorizarão os conteúdos, mas ainda aprenderão. Dessa forma, o ensino nas escolas terá uma alternativa metodológica para auxiliar no processo de ensino-aprendizagem, embora seja necessário haver um planejamento para que esse recurso seja bem utilizado.

\footnotetext{
${ }^{2}$ Programa Nacional de Integração da Educação Profissional com a Educação Básica na Modalidade de Educação Jovens e Adultos.

${ }^{3}$ Atividades relacionadas a jogos, brincadeiras e divertimentos.
} 


\section{OBJETIVOS E METODOLOGIA}

Neste artigo temos como objetivo geral discutir a importância de atividades lúdicas no desenvolvimento da Educação Matemática, e como objetivos específicos: refletir sobre o papel do lúdico no surgimento de novas teorias matemáticas; discutir sobre o papel e a responsabilidade dos professores nas mudanças significativas que nos são impostas hoje, tendo em vista uma aprendizagem matemática mais significativa; e apresentar algumas atividades lúdicas: paródias matemáticas, jogos e truques matemáticos e, a partir dessas atividades, discutir o tratamento matemático, os conteúdos e as metodologias neles contidos.

Com o intuito de alcançar os objetivos propostos, apresentamos algumas atividades como estratégia facilitadora do processo de assimilação do conhecimento matemático na perspectiva do desenvolvimento de uma prática de ensino de qualidade, identificando os fatores que favorecem ou dificultam o seu uso como estratégia de ensino. Mais especificamente, queremos revelar uma alternativa metodológica adequada para a aquisição do conhecimento matemático e identificar os fatores que favorecem o seu uso.

$\mathrm{Na}$ tentativa de atender às diretrizes anteriormente enunciadas, a metodologia que propomos é a utilização de atividades lúdicas, pois possibilita transformar os envolvidos no aprendizado (discentes e docentes) em sujeitos do processo de construção do conhecimento, colocando a realidade e o cotidiano do aluno como elemento chave para o estudo da disciplina e conhecimentos envolvidos nessa área. Como consequências, algumas mudanças na forma de ver e encaminhar a aula, a relação professor-aluno e a avaliação deverão ser modificadas no âmbito dessa proposta.

Com base no que foi exposto apresentamos nossa metodologia, que se encontra dividida em quatro momentos. O primeiro momento consiste em conhecer o público, motivar uma discussão a partir da opinião deles sobre a flexibilidade que devemos dar a nossa maneira de agir, enquanto professores ou estudantes, sempre com o objetivo de sermos um auxílio no processo de ensino e aprendizagem das atividades matemáticas.

No segundo momento, apresentamos algumas paródias com conteúdos matemáticos (NEGREIRO, 2002), além da proposta de elaboração e de realização de paródias. As paródias podem ser elaboradas a partir de algum conteúdo matemático, tendo como regrabase a explicação desse conteúdo e a adequação desse texto à melodia da música escolhida. A seguir, realizamos um concurso em que são escolhidas as paródias que melhor se adéquam à regra estabelecida. Apresentamos ainda várias questões de adivinhas e o modelo de um cordel que aborda a avaliação em novos moldes. Uma breve discussão também é imprescindível com o intuito de sanar dúvidas e enriquecer todo o processo.

Realizamos ainda algumas mágicas, mostrando a sua importância na valorização e aquisição do conteúdo matemático. Nesse momento será valorizado, de maneira especial, o raciocínio lógico dos discentes e a sua habilidade em apresentar suas respostas. De acordo com Malagutti (2008, p.9),

"a arte de adivinhar ou prever números e cálculos aritméticos faz parte de nossa cultura matemática desde a primeira infância. Muitos autores têm dedicado seu tempo a escrever livros sobre truques (...), e essa arte parece encantar as crianças até hoje, principalmente se acompanhada de lendas e mistérios." 
É exatamente este tipo de atividade que queremos abordar para encantar, motivar e enriquecer a criatividade dos participantes, pois percebemos que os jovens e adultos também se encantam com esse processo.

Por fim, no último momento, realizamos algumas atividades que auxiliam a dedução de fórmulas com atividades simples e práticas, como, por exemplo, a Torre de Hanoi e o quadrado mágico, atividades conhecidas há séculos e que trazem uma grande riqueza de conteúdo e auxílio à aprendizagem. Ainda neste momento buscamos discutir, por meio da aprendizagem dos participantes, como difundirmos a idéia de junção das atividades lúdicas com o ensino de Matemática na nossa prática do dia-a-dia escolar, mesmo com todos os desafios de cumprirmos todo o conteúdo programático num período específico. Apresentamos a seguir um exemplo de atividade utilizada:

\section{EXEMPLO DE ATIVIDADE: RESGATANDO O DÍGITO PERDIDO}

O mágico pede a uma pessoa para escrever, em segredo, um número inteiro de quatro ou cinco algarismos (o número de algarismos é irrelevante para esta brincadeira), que não precisam ser diferentes entre si, e que não faça uso do algarismo 0. Em seguida, o mágico pede à pessoa para calcular a soma dos algarismos de seu número.

Suponhamos que a pessoa escreva o número 24 543. A soma dos algarismos deste número é 18. O mágico pede, então, que a pessoa suprima um dos algarismos de seu número, riscando-o, e, com os algarismos que restaram, forme um novo número, alterando a ordem dos algarismos como quiser.

Conforme o exemplo que estamos utilizando, a pessoa pode suprimir de seu número original o algarismo 5 e, em seguida, com os algarismos restantes, formar o número 3442. Assim, o mágico pede à pessoa para subtrair desse novo número (encurtado e com seus algarismos aleatoriamente embaralhados), a soma dos algarismos do número original. No nosso exemplo a pessoa calculará:

$3442-18=3424$

O mágico pede à pessoa que lhe informe o resultado dessa subtração e, a partir do resultado, revela imediatamente qual foi o algarismo suprimido do número original.

\section{DESMASCARANDO O FEITICEIRO:}

Vamos explicar o truque sem demonstrar as justificativas aritméticas. Um número é divisível por 9 se a soma de seus algarismos for divisível por 9. Quando o número não é divisível por 9, ele e a soma de seus algarismos deixam o mesmo resto quando divididos por 9.

Por exemplo, para saber qual é o resto da divisão de 45176 por 9 , calculamos $4+5+1+7$ $+6=23$. O resto da divisão de 23 por 9 é 5 . Portanto, o resto da divisão de 45176 por 9 também é 5.

$4+5+1+7+6=23$ 
$\mathbf{2}+\mathbf{3}=\mathbf{5}$ (repetindo o procedimento de somar os algarismos) e chegamos ao número $\mathbf{5}$, resto da divisão de $\mathbf{4 5 1 7 6}$ por 9.

Como consequência disso, a diferença entre um inteiro e a soma de seus algarismos é sempre divisível por $\mathbf{9}$, já que ambos deixam o mesmo resto na divisão por $\mathbf{9}$.

Como exemplo, a diferença $45176-(4+5+1+7+6)=45153$ é divisível por 9 :

$45176-(4+5+1+7+6)$

$=(4 \times 10000+5 \times 1000+1 \times 100+7 \times 10+6)-(4+5+1+7+6)$

$=4 \times 9999+5 \times 999+1 \times 99+7 \times 9$.

Agora, se calculamos a soma dos dígitos de um número inteiro divisível por 9 devemos obter um número divisível por 9. Se aplicarmos o procedimento de: calcular a soma dos dígitos de um inteiro, calcular novamente a soma dos dígitos do resultado e repetir o cálculo da soma dos dígitos a cada novo resultado, a partir de um número divisível por 9 , eventualmente chegaremos a um inteiro positivo, de um só dígito, divisível por $\mathbf{9}$, que só pode ser...9.

E quanto à explicação sobre a descoberta do dígito perdido?

Suponhamos que a pessoa submetida ao truque mágico tenha suprimido o dígito 7 do número 45176 e que, com os algarismos restantes, formou o número 4561: a diferença $4561-(4+5+1+7+6)=4561-23$ já não será divisível por 9 , pois o dígito 7 foi descartado do primeiro número.

Agora, 4561 - 23 = 4538 é um resultado informado ao mágico. O cálculo iterado da soma dos dígitos deste resultado informado resulta em:

$4+5+3+8=29$

$2+9=11$

$1+1=2$

Assim, revela-se ao mágico que não foi obtido um 9 ao final por falta de 7 unidades, informando-lhe que este é o dígito perdido. Apresentaremos também a obtenção de raízes quadrada e cúbica por um processo simples e prático Malagutti (2008, p.16 e 17).

\section{MATEMÁTICA NO ENSINO MÉDIO: DESAFIOS E POSSIBILIDADES}

Ao elaborarmos este estudo, partimos de alguns pressupostos em relação à construção do conhecimento matemático e à participação do aluno e do professor nessa construção, a saber: (1) o conhecimento científico é uma construção coletiva, que vem sendo desenvolvida ao longo do tempo, pelo acúmulo das experiências e da criatividade dos homens; (2) a ciência não pode ser considerada neutra nem acabada. Por ser elaborada por pessoas, ela reflete as visões de uma época; (3) o estabelecimento de relações dos conteúdos escolares com atividades e conhecimentos do cotidiano do aluno como fator facilitador da aprendizagem; (4) a expectativa de transformar as concepções espontâneas ${ }^{4}$

\footnotetext{
${ }^{4}$ Concepções Espontâneas ou Conceitos Espontâneos são conceitos naturais ao nosso pensamento que não nos remetem a nenhum raciocínio lógico ou científico, sendo o nível mais primitivo de informação. São formados na fase de nossa vida em que estamos aprendendo a lidar com o meio que nos cerca. Segundo
} 
dos alunos em conhecimentos escolares deve ser sempre uma meta a ser perseguida; (5) o papel do profissional professor sempre foi e sempre será fundamental à execução de qualquer proposta de ensino.

Além desses pressupostos, estamos levando em conta as tendências metodológicas em Educação Matemática, que são: o uso de materiais concretos e jogos, a Etnomatemática ${ }^{5}$, a resolução de problemas como estratégia cognitiva, a história da Matemática e o ensino da Matemática escolar e o uso de computadores e calculadoras em sala de aula. Esses aspectos apontam para a importância de uma formação geral, com uma boa aquisição de conteúdos tradicionais das ciências e das artes associados ao desenvolvimento de estruturas capazes de operacionalizá-los em situações presentes na realidade social.

O ensino-aprendizagem de matemática nas escolas públicas do Brasil tem enfrentado muitas dificuldades e está longe de ser tido como um ensino de qualidade. Os problemas são vários, desde currículos desatualizados, escassez de recursos materiais nas escolas, baixos salários, deficiência na formação dos profissionais envolvidos e falta de incentivos e de perspectiva.

Embora os problemas sejam gravíssimos, não podemos ficar de braços cruzados esperando que apareça um culpado e que alguém mostre a solução. A educação básica necessita de mudanças e nós, educadores, temos o compromisso de procurar resolver ou, no mínimo, amenizar a situação.

O ambiente de aula deve passar por uma mudança no seu significado, deixando de ser um local onde os alunos vão para apenas ouvir o professor, para se transformar num lugar de trabalho de produção de conhecimento ou num hábitat natural de pesquisa. Isso não significa que as formas de trabalho anteriores deixarão de existir. $O$ quadro de giz continuará tendo sua importância e a fazer parte do contexto, pois ainda é um dos recursos mais usados para que o professor possa orientar a condução de suas atividades. $\mathrm{O}$ mesmo critério é dado à aula tradicional, que também não deixa de existir. Entretanto, outras formas de interação do professor com a turma podem ser levadas em consideração para a inserção de inovações no processo educativo, não se restringindo unicamente ao uso de atividades lúdicas.

A sala de aula é um espaço de reflexão, discussão sobre ensino e aprendizagem e aperfeiçoamento do professor na medida em que ele busca explorar novas formas de ensinar e alcançar o objetivo de um determinado conteúdo. Segundo Malba Tahan (1962, p.62), "O professor de Matemática, que dispõe de um bom laboratório, poderá, com a maior facilidade, motivar seus alunos por meio de experiências e orientá-los mais tarde, com a maior segurança, pelo caminho das pesquisas mais abstratas". Tanto o laboratório do pesquisador, quanto o laboratório didático do professor é de extrema importância para o processo ensino-aprendizagem. No primeiro, o pesquisador comprova a importância de desenvolver determinadas atividades com os alunos e, no segundo, essas atividades são colocadas em prática, reafirmando ou refutando as conclusões do pesquisador.

Piaget, estes conceitos são formados de dentro para fora, ou seja, a partir de experiências relacionadas a contatos com objetos ou situações do cotidiano.

${ }^{5}$ Para D’Ambrosio (1990; 2001), etnomatemática significa reconhecer que todas as culturas, todos os povos, desenvolvem maneiras de explicar, de conhecer, de lidar com a sua realidade, e que isso está em constante evolução. 
Neste contexto, novas abordagens metodológicas surgem como um recurso bastante eficiente, desde que usadas adequadamente. E ressaltamos ainda que, para produzir atividades criativas, não devemos esperar somente pelos recursos escassos do governo. Podemos e devemos utilizar material reciclável de baixo custo e acessível a toda a população, exercendo a nossa cidadania e formando cidadãos para o futuro.

Com a globalização, não há dúvida de que um dos grandes desafios é o preparo adequado dos cidadãos, de modo a possibilitar tanto sua integração ao momento atual quanto lhes fornecer uma preparação para o acompanhamento do contínuo processo da evolução tecnológica com todas as suas consequências.

A Matemática é um dos suportes básicos para essas conquistas tecnológicas. Os projetos educacionais que são comprometidos com a formação das futuras gerações que comporão a sociedade futuramente levam essa consideração muito a sério. A Matemática fornece ferramentas que permitem ao homem sintetizar, generalizar, modelar e submeter esses modelos a provas e verificações prévias, possibilitando ensaios, propiciando condições confiáveis de previsibilidade, cujas aplicações e utilização cada vez mais frequentes tornam a Matemática imprescindível atualmente.

A ampliação desta disciplina acontece não somente pelas constantes pesquisas nessa área e pelo uso frequente de programas de computador, mas também pelos mais diferentes ramos da atividade humana contemporânea. Ter acesso a essas informações, ou ser capaz de entender sua importância no contexto atual, é condição imperiosa para a contribuição no processo de desenvolvimento científico e tecnológico do país, e o despertar de uma consciência crítica sobre esse desenvolvimento faz parte da preparação para uma efetiva participação democrática do cidadão.

A verdade é que a junção de todo o conhecimento matemático produzido atualmente ainda não é suficiente para explicar todos os complexos fenômenos do mundo. Mas, mesmo esse conhecimento insuficiente está muito além da realidade das nossas salas de aula. Muitos não devem mesmo fazer parte dos currículos escolares atuais. Entretanto, algumas idéias fundamentais e princípios básicos desses conhecimentos podem ser organizados, para efeitos didáticos, para que sejam compreensíveis aos nossos alunos, de modo a dar-lhes a correta impressão de que os conhecimentos são produzidos na medida das necessidades de se resolverem problemas do nosso mundo, o que, por si só, é a principal razão da existência da disciplina Matemática nos currículos.

Dessa forma, permitimos que o aluno perceba que os conceitos são frutos do trabalho humano, da observação e da experimentação ou da elaboração mental para a obtenção de conclusões, da comparação e da crítica dos resultados obtidos, da re-elaboração e da reacomodação dos conhecimentos construídos ao longo do tempo, bem ao contrário do que aparece escrito, de maneira pronta e acabada, em vários livros didáticos.

Independentemente dos programas de ensino nas escolas, os conhecimentos matemáticos são produzidos diariamente por uma necessidade compulsória e interna da própria ciência, bem como são provocados pela multiplicidade das atividades humanas. A cada momento, novas necessidades são geradas e novos desafios, oriundos da própria Matemática ou provocados por necessidades de outras áreas, são propostos, cuja solução requer pessoas preparadas, criativas, capazes de enfrentar esses desafios. Nisso a escola e, particularmente o professor de Matemática, tem um papel importante ao identificar, orientar e estimular o 
potencial dos alunos, que vão constituir as futuras gerações de trabalhadores utilizando a Matemática num processo de renovação permanente.

Cabe ao professor de Matemática, e especificamente a ele, levar os alunos à construção da necessária abstração matemática a partir da motivação de questões sugeridas pela vida cotidiana, transformando concepções espontâneas em conhecimentos mais elaborados, compatíveis com os parâmetros atuais das ciências. Como afirma Ribeiro e Nuñes (2004, p.30),

\footnotetext{
A estrutura cognitiva contém as informações armazenadas pelos(as) alunos(as), e apresenta uma determinada organização. Esse conteúdo informacional, previamente assimilado, transforma-se em uma estrutura que permite a inclusão de novos dados (a compreensão pelas relações que se estabelecem), mecanismo necessário ao processo de aprendizagem significativa.
}

Dessa forma, os conteúdos que tradicionalmente compõem os currículos de Matemática fazem parte de um corpo estruturado de conhecimentos acumulados ao longo do tempo, o qual deve ser analisado e avaliado tanto por especialistas da área de ensino quanto por profissionais de Matemática, a respeito de sua atualização ou adaptação às necessidades locais e temporais. Não se pode incluir ou excluir conteúdos apenas por modismo ou por interesse de grupos particulares, sob pena de prejudicar gerações pela introdução ou aprofundamento de diferenças regionais, diferenças sociais ou outras.

Além da seleção dos conteúdos, podemos organizá-los didaticamente de maneira diferente da que vem sendo feita, de modo a apresentá-los numa perspectiva contextualizada e interdisciplinar, como é natural de se conceber uma disposição curricular que atenda às características da atualidade. O professor não deve apontar a necessidade do vencimento total do conteúdo como empecilho à modificação na seleção dos conteúdos.

Portanto, é preciso propiciar ao aluno tanto uma base sólida de conteúdos que o torne capaz de constituir-se como sujeito de seu próprio processo de evolução, atendendo ao perfil requerido de autônomo intelectualmente, criativo, capaz de perceber um mundo em constante transformação como oportunidade para o desenvolvimento de atitudes comportamentais que lhe darão condições de continuar aprendendo continuadamente, mais como uma necessidade de participação no processo evolutivo do que por promessas de sucesso.

Entendemos que os conteúdos curriculares de Matemática constantes das propostas de ensino das escolas deverão se voltar ao desenvolvimento de habilidades numéricas, habilidades algébricas, habilidades geométricas e habilidades gráficas. Qualquer que seja o peso que o professor dê a pressupostos gerais para a elaboração do seu projeto pedagógico, o desenvolvimento dessas habilidades deve ser o principal objetivo da sua tarefa no ensino da Matemática. É nesse sentido que entendemos a concepção de eixos temáticos contemplados nos PCNs (BRASIL, 1997).

Atualmente, o Ensino da Matemática tem sido discutido com mais freqüência. O objetivo da educação tem conduzido a discussão a vários ramos, desde a formação da mão-de-obra qualificada até a formação do cidadão para o exercício de sua cidadania plena. 
A questão primordial, no entanto, seria unir esses ramos, fornecendo uma educação que ao mesmo tempo forme mão-de-obra qualificada sem descuidar da formação do ser humano para o mundo, para a vida em sociedade. Segundo Mendes (2006, p.13):

\begin{abstract}
... a resposta para formar o cidadão universal sem descuidar do profissional está no desenvolvimento da autonomia competente dos indivíduos, pois uma pessoa autônoma é capaz de tomar decisões a partir de suas próprias análises, que associadas à competência técnico-política, sempre encontram caminhos para superar os obstáculos apresentados no dia-a-dia da sua vida profissional e social.
\end{abstract}

Acreditamos que o desenvolvimento da autonomia competente dos seres humanos seja realmente uma saída para a formação do indivíduo apto a enfrentar os obstáculos da vida pessoal e profissional e que a sala de aula seja um dos ambientes propícios ao desenvolvimento desta autonomia, visto que é um local de descoberta, de troca de conhecimentos, o que dá um incentivo a mais para o nosso aluno.

O ser autônomo desenvolve o trabalho de investigação que enriquece a discussão em sala de aula, além de familiarizar o aluno com as diversas formas de expressão escrita e oral. É interessante que o professor tenha uma atitude receptiva a esse tipo de trabalho e entenda-o como um processo que pode trazer resultados significativos para a formação dos alunos.

Também não poderíamos deixar de enfatizar a importância da comunicação para o ensino da matemática. A comunicação é um componente importante no contexto educativo e indispensável entre professores e alunos. Essa comunicação auxilia a aprendizagem dos alunos em relação à linguagem simbólica da matemática.

A linguagem é importante para a construção do conhecimento matemático e é por meio dela que o aluno adquire os conceitos sobre a sociedade em que está inserido. A linguagem é importante para o desenvolvimento mental da criança e também tem uma função social e comunicativa.

Para que haja uma melhor compreensão da aula, são necessárias, atividades adequadas ao contexto social dos alunos, que os estimulem a verbalizar o raciocínio desenvolvendo as habilidades de investigação, comunicação e linguagem. Acreditamos que atividades lúdicas propiciam a articulação entre o conhecimento escolar e os diversos saberes do educando, sendo uma das alternativas metodológicas mais propícias à construção do conhecimento matemático pretendido nestas atividades.

Todos os alunos podem e devem compreender e usar diariamente as ideias matemáticas, pois tal habilidade não deve ser propriedade apenas de uma minoria que tenha mais afinidade com o raciocínio lógico-matemático. A Matemática está presente nas atividades humanas em maior ou menor complexidade e, ao perceber isso, o aluno compreende o mundo à sua volta, podendo atuar nele.

Nesse sentido, a instalação de um laboratório didático de Matemática, a criação de paródias, a elaboração de atividades vinculadas à etnomatemática e à modelagem matemática são propostas essenciais, motivadoras e geradoras de conhecimento, que devem fazer parte do currículo dos mais diversos cursos e níveis de ensino, pois, como vemos nos PCNs, é importante ter um novo olhar para o aluno e ir "criando condições para 
a sua inserção num mundo em mudança e contribuindo para desenvolver as capacidades que deles serão exigidas em sua vida social e profissional” (BRASIL, 1999, p. 81).

Vale destacar que para se desenvolverem tais projetos, é preciso valorizar não só a experiência do aluno fora da escola, como o conteúdo trabalhado com ele deve ser significativo, fazendo-o sentir a importância de que conhecer determinado assunto tem para a sua vida e para entender o mundo ao seu redor. Assim, torna-se necessário conhecer a clientela e as potencialidades da comunidade em que vive o educando, para se implantar um projeto de forma mais segura e eficaz.

De acordo com Gauthier (2003, p. 27) "para que os professores possam superar a chamada metodologia da superficialidade, geralmente tão utilizada na construção de saberes do senso comum, supõe incorporar a pesquisa como um dos componentes da formação". Sendo assim, é extremamente importante estarmos sempre pesquisando e buscando novas alternativas, pois o mundo está em constantes e rápidas mudanças. Assim, estamos sempre aprendendo coisas novas, quer com o aluno, em nossa própria vivência de sala de aula, quer observando a comunidade, consultando grupos de estudos e pesquisas ou publicações, ou ainda trocando ideias e experiências em cursos, encontros, congressos, para melhorar a atuação e o desempenho do aluno a cada dia.

É imprescindível lembrarmos que não nascemos para viver em solidão e que estamos sempre procurando outras pessoas com quem conviver. Nessa relação de convivência, a troca é inevitável e, de acordo com as necessidades diárias, as adaptações tornam-se primordiais. Freire (2000, p. 79) afirma: "Ninguém nasce feito. Vamos nos fazendo aos poucos, na prática social de que tomamos parte". Os grupos se estabelecem, constroem sua identidade através do desenvolvimento de valores, crenças, estratégias cognitivas e práticas, que evidenciam os aspectos culturais característicos da formação social originária dos indivíduos. Certamente, essas manifestações individuais e coletivas são evidenciadas de acordo com as necessidades primordiais e os recursos naturais e ambientais disponíveis em cada contexto.

\section{CONCLUSÃO}

Nosso interesse em multiplicarmos essa prática é porque sabemos - e nossa experiência em sala de aula confirma - que muitas são as dificuldades encontradas no ensino-aprendizagem da Matemática, como já foi abordado anteriormente. Ao longo de décadas, essa disciplina vem sendo ensinada de forma mecânica, passiva e desvinculada da realidade do aluno. Isso faz com que muitos alunos se sintam desmotivados para construir conhecimentos matemáticos, qualificando a disciplina de difícil, chata e enfadonha.

Esses efeitos negativos do ensino da Matemática são antigos e foram gerados a partir de um ensino desvinculado da realidade de quem aprende. Os conteúdos eram apresentados de forma pronta e acabada, priorizando uma memória mecânica, em vez de uma construção da compreensão de conceitos, o que tornou o aluno apático, obediente, sem criatividade e sem iniciativa (MENDES, 2006).

Desse modo, entendemos que se faz necessário um trabalho voltado para superar essas dificuldades. No entanto, para que haja uma mudança de postura da escola em relação ao desenvolvimento do ensino da Matemática é preciso que se entenda que professor e aluno 
podem, juntos, encaminhar a construção do saber, de modo que o aluno pesquise e, por meio da descoberta, estabeleça relações entre conceitos e estruturas matemáticas a serem apreendidos, e o professor seja o mediador, para que esse conhecimento seja incorporado à estrutura cognitiva do aluno (MENDES, 2006).

Assim, neste trabalho apresentamos atividades e reflexões que marcaram esta trajetória educacional, com a finalidade de registrar as experiências significativas realizadas em sala de aula e que motivaram a participação efetiva dos alunos. Além disso, realizamos determinadas atividades efetivando a discussão e a troca de experiências. Freire (2001, p. 29) afirma que "os homens são capazes de agir conscientemente sobre a realidade objetivada". Por sabermos que as oportunidades de vivência ampliam essa conscientização, acreditamos que o trabalho ora apresentado trará uma gama de sugestões $\mathrm{e}$ questionamentos a respeito.

Em vários cursos que ministramos, inclusive em outras turmas de $\mathrm{EJA}^{6}$, compartilhamos experiências com uso e (re)criação de paródias como um recurso didático para o ensinoaprendizagem da Matemática. Elaboramos jogos e os construímos junto com os alunos, desenvolvemos atividades com truques e mágicas e, unindo todas essas ideias aos softwares matemáticos, vimos nascer opiniões para enriquecer as aulas de Matemática. Tais experiências foram reveladoras, dinâmicas e criativas. Os alunos ficaram entusiasmados e superaram as expectativas previstas no planejamento. $\mathrm{O}$ aumento das suas capacidades de expressão ficou evidente e a aprendizagem ocorreu de forma agradável e prazerosa.

Entendemos que esse trabalho deve ser implantado nas instituições de ensino, dando oportunidade aos alunos de vivenciar os conteúdos matemáticos de forma mais descontraída.

Diante disso, acreditamos que os alunos precisam participar de experiências diversas com o intuito de desenvolverem todas as potencialidades necessárias à participação na sociedade em que vivem. Para que o desenvolvimento integral do educando seja efetivo e consistente, a motivação é essencial. Com esse pensamento desenvolvemos atividades lúdicas nas turmas em que atuamos e transformamos as referidas atividades no relato que ora propomos. Planejamos apresentar atividades diversas adquiridas ao longo de nossa trajetória educacional, em experiências em sala de aula, congressos, palestras, entre outros. Acreditamos que, dessa forma, deixaremos um gostinho de "quero mais" para todos os envolvidos no processo educacional.

\section{REFERÊNCIAS}

1. BRASIL. Ministério da Educação. Secretaria de Educação Média e Tecnológica. Parâmetros Curriculares Nacionais: ensino médio: ciência da natureza, matemática e suas tecnologias. Brasília: MEC/SEMT, 1999.

2. BRASIL. Ministério de Educação e do Desporto. Secretaria de Educação Fundamental. Parâmetros curriculares nacionais: matemática. Brasília, 1997.

3. D’AMBROSIO, Ubiratan. Etnomatemática: elo entre as tradições e a modernidade. Belo Horizonte: Autêntica, 2001.

\footnotetext{
${ }^{6}$ Educação de Jovens e Adultos.
} 
4. FREIRE, Paulo. Conscientização: teoria e prática da libertação: uma introdução ao pensamento de Paulo Freire. São Paulo: Centauro, 2001.

5. FREIRE, Paulo. Política e Educação. São Paulo:Cortez, 2000 (coleção Questões da Nossa Época: v.23).

6. GAUTHIER, Clermont; NUÑEZ, Isauro Béltran; RAMALHO, Betania Leite. Formar o Professor e Profissionalizar o Ensino. Porto Alegre: Sulina, 2003.

7. MAlaguTTI, Pedro Luiz; SAMPAIO, João Carlos. Mágicas, Matemática e outros mistérios. São Carlos: EduFSCar, 2008.

8. MENDES, Iran Abreu. Matemática e investigação em sala de aula: tecendo redes cognitivas na aprendizagem. Natal: Flecha do Tempo, 2006.

9. MENDES, Iran Abreu. Matemática por atividades: sugestões para a sala de aula. Natal: Flecha do Tempo, 2006.

10. NEGREIRO, Professor. CD Cantando A Matemática. Paraíba: Stúdio AUDIOGRÀFIC, 2002.

11. RIBEIRO, Raimunda P.; NUÑEZ, Isauro Béltran. A aprendizagem significativa e o ensino de Ciências Naturais. In: NUÑEZ, Isauro Béltran; RAMALHO, Betania Leite (Orgs.). Fundamentos do ensino-aprendizagem das ciências naturais e da matemática: o novo ensino médio. Porto Alegre: Sulina. 2004. p 29-42.

12. TAHAN, Malba. Matemática Divertida e Delirante. São Paulo: Saraiva, 1962. 